\title{
A New Algorithm for Simultaneous Retrieval of Aerosols and Marine Parameters
}

\author{
Taddeo Ssenyonga ${ }^{1, *(\mathbb{D})}$, Øyvind Frette ${ }^{2}$, Børge Hamre ${ }^{2} \mathbb{D}$, Knut Stamnes ${ }^{3}$, Dennis Muyimbwa ${ }^{1}$, \\ Nicolausi Ssebiyonga ${ }^{1}$ and Jakob J. Stamnes ${ }^{2}$ \\ 1 Department of Physics, Makerere University, Kampala P.O. Box 7062, Uganda; \\ dennis.muyimbwa@mak.ac.ug (D.M.); nicolausi.ssebiyonga@mak.ac.ug (N.S.) \\ 2 Department of Physics and Technology, University of Bergen, 5020 Bergen, Norway; \\ Oyvind.Frette@uib.no (Ø.F.); Borge.Hamre@uib.no (B.H.); Jakob.Stamnes@uib.no (J.J.S.) \\ 3 Department of Physics, Stevens Institute of Technology, Hoboken, NJ 07030, USA; kstamnes@stevens.edu \\ * Correspondence: taddeo.ssenyonga@gmail.com; Tel.: +256-772-981906
}

check for updates

Citation: Ssenyonga, T.; Frette, $\varnothing$.; Hamre, B.; Stamnes, K.; Muyimbwa, D.; Ssebiyonga, N.; Stamnes, J.J. A New Algorithm for Simultaneous Retrieval of Aerosols and Marine Parameters. Algorithms 2022, 15, 4. https://doi.org/10.3390/a15010004

Academic Editors: Yunquan Zhang and Liang Yuan

Received: 9 November 2021 Accepted: 22 December 2021 Published: 24 December 2021

Publisher's Note: MDPI stays neutral with regard to jurisdictional claims in published maps and institutional affiliations.

Copyright: (c) 2021 by the authors. Licensee MDPI, Basel, Switzerland. This article is an open access article distributed under the terms and conditions of the Creative Commons Attribution (CC BY) license (https:// creativecommons.org/licenses/by/ $4.0 /)$.

\begin{abstract}
We present an algorithm for simultaneous retrieval of aerosol and marine parameters in coastal waters. The algorithm is based on a radiative transfer forward model for a coupled atmosphere-ocean system, which is used to train a radial basis function neural network (RBF-NN) to obtain a fast and accurate method to compute radiances at the top of the atmosphere (TOA) for given aerosol and marine input parameters. The inverse modelling algorithm employs multidimensional unconstrained non-linear optimization to retrieve three marine parameters (concentrations of chlorophyll and mineral particles, as well as absorption by coloured dissolved organic matter $(\mathrm{CDOM})$ ), and two aerosol parameters (aerosol fine-mode fraction and aerosol volume fraction). We validated the retrieval algorithm using synthetic data and found it, for both low and high sun, to predict each of the five parameters accurately, both with and without white noise added to the top of the atmosphere (TOA) radiances. When varying the solar zenith angle (SZA) and retraining the RBF-NN without noise added to the TOA radiance, we found the algorithm to predict the CDOM absorption, chlorophyll concentration, mineral concentration, aerosol fine-mode fraction, and aerosol volume fraction with correlation coefficients greater than $0.72,0.73,0.93,0.67$, and 0.87 , respectively, for $45^{\circ} \leq \mathrm{SZA} \leq 75^{\circ}$. By adding white Gaussian noise to the TOA radiances with varying values of the signal-to-noise-ratio (SNR), we found the retrieval algorithm to predict CDOM absorption, chlorophyll concentration, mineral concentration, aerosol fine-mode fraction, and aerosol volume fraction well with correlation coefficients greater than $0.77,0.75,0.91,0.81$, and 0.86 , respectively, for high sun and SNR $\geq 95$.
\end{abstract}

Keywords: algorithms; radiative transfer; remote sensing; atmospheric optics; neural networks; CDOM absorption; chlorophyll concentration; mineral concentration; aerosol

\section{Introduction}

Algorithms for retrieval of atmospheric and marine parameters from measurements of back-scattered radiances at several wavelengths by instruments deployed on earthorbiting satellites (ocean color data) have been developed over the past few decades. The earliest ocean color remote sensing algorithms were based on a two-step approach. First, an atmospheric correction was carried out to estimate the aerosol optical depth (AOD) at a near-infrared (NIR) channel (865 nm for Sea Wide Field of view (SeaWiFS) sensor), for which the ocean was assumed to be black (the NIR black-pixel approximation (NIR-BPA)). Second, AOD values for wavelengths in the visible range were obtained by extrapolation and used to generate water-leaving radiances [1-5]. The two-step algorithms employ regression or look-up table matching based on bio-optical models to estimate chlorophyll concentration from visible-channel water-leaving radiances. The weakness of 
this two-step approach is its reliance on the inaccurate NIR-BPA assumption, according to which atmospheric and oceanic radiative transfer processes can be de-coupled [6,7].

To circumvent the problems associated with the two-step approach a one-step retrieval scheme that accounts for radiative coupling between the atmosphere and the ocean was proposed [8]. Amongst the first investigators to implement the one step retrieval scheme were Chomko and Gordon [9], Gordon et al. [10], Frette et al. [11], and Stamnes et al. [12]. The algorithms presented in [9,10] are based on using a bio-optical model of Gordon et al. [13] to relate the water leaving reflectance to the water constituents, and on using an aerosol model to determine the contribution of absorbing aerosols to the satellite measured reflectance. Using these algorithms, one obtains a combination of ocean parameters and aerosol model that gives a best fit to the measured reflectance throughout the spectrum. Frette et al. [11] and Stamnes et al. [12] employed a well-tested radiative transfer model (RTM) for a coupled atmosphere-ocean system [14,15] to compute radiances at the top of the atmosphere (TOA) and an iterative inversion scheme for simultaneous retrieval of marine and atmospheric parameters. The algorithm in [12] was capable of retrieving two aerosol parameters and one marine parameter, which is appropriate for open-ocean water bodies in which chlorophyll is the main marine retrieval parameter of interest, whereas the algorithm in [11] was capable of retrieving three marine parameters and one aerosol parameter. Even though the algorithms in [11,12] are more accurate than the two-step algorithms, they can not easily be extended to retrieve more parameters. The algorithm of Chomco et al. [16] combines the bio-optical model of Garver and Siegel [17] with the spectral optimization algorithm of Chomco and Gordon [9] to retrieve a set of ocean parameters (CDOM at $443 \mathrm{~nm}$, chlorophyll concentration, and backscattering coefficient of particulate matter at $443 \mathrm{~nm}$ ) along with estimates of aerosol optical properties. However, this algorithm is based on aerosols having a wavelength-independent, real refractive index, and therefore cannot be applied to absorbing aerosols.

Steinmetz et al. [18] developed an atmospheric correction POLYnomial based algorithm applied to MERIS (POLYMER) algorithm which can retrieve ocean color parameters in the whole sun glint pattern. The algorithm employs a method of spectral matching where it first models the spectral reflectance of the atmosphere and sun glint by use of a polynomial and then employs a water reflectance model.

Li et al. [19] developed a method for simultaneous retrieval of two aerosol parameters and three marine parameters based on a linearized, coupled atmosphere-ocean forward RTM [20] and optimal estimation to solve the inverse problem. The retrieved aerosol parameters included the AOD at $865 \mathrm{~nm}$ and a bimodal fraction of large vs. small particles. The retrieved marine parameters included the chlorophyll concentration, the detrital/dissolvedmatter absorption at $443 \mathrm{~nm}$, and the backscattering coefficient at $443 \mathrm{~nm}$. The algorithm in [19] employs an iterative, non-linear optimal estimation scheme, which uses the forward RTM at each iteration step to simulate TOA radiances and Jacobians associated with the current state vector, whose components are the five retrieval parameters. The use of the forward RTM at each step of the iteration process for computing TOA radiances and Jacobians associated with the current state vector is computationally demanding.

Algorithms employing neural networks have been used in remote sensing of the atmosphere-ocean system because they are fast and can retrieve in one step both marine and atmospheric parameters. Takana et al. [21] developed an algorithm which employs the Stuttgart Neural Network Simulator [22] for constructing and training the neural network. Their algorithm inverts the radiative transfer procedure to retrieve three ocean parameters (chlorophyll concentrations, suspended organic matter, and yellow substance) from normalized water-leaving radiance data of the ocean color and temperature sensor (OCTS) of the Advanced Earth Observing Satellite (ADEOS). 
Jamet et al. [23] developed the NeuroVaria neural network algorithm which retrieves atmospheric and ocean parameters by minimising the difference between the observed satellite reflectance and that computed from radiative transfer simulations using artificial neural networks. Their method takes care of absorbing aerosols by using the Junge power law [24] of particle size distribution, and the computation of the partial derivatives of the cost function is accomplished by using the gradient method. Brajard et al. [25] modified the NeuroVaria algorithm by Jamet et al. [23]. The improved algorithm is more efficient in minimizing the iterative cost function.

Schiller and Doerfer [26] developed an algorithm which employs neural networks to parameterize the inverse relation between concentrations and reflectances. Their algorithm applies to case II waters, and is capable of retrieving three marine (chlorophyll concentration, suspended matter and CDOM) parameters and one atmospheric (aerosol concentration) parameter.

Stamnes et al. [27] modified Li et al. [19] algorithm and developed an inversion scheme named "Ocean Color: Simultaneous Marine and Aerosol Retrieval Tool" (OCSMART). The OC-SMART retrieval algorithm is faster than that in [19], because instead of employing a linearized forward RTM to compute required TOA radiances and Jacobians, it employs a radial basis function neural network (RBF-NN) to establish an analytical relationship between input/retrieval parameters and simulated TOA radiances. The RBF$\mathrm{NN}$ also provides analytical expressions for the Jacobians. In the OC-SMART algorithm, the retrieval is based on optimal estimation combined with a Levenberg-Marquardt scheme for speeding up convergence when determining those parameters which provide the best fit to the TOA radiance measurements. The aim of this study is to develop a method for simultaneous retrieval of aerosol and water parameters in high-latitude coastal waters based on a coupled atmosphere-ocean radiative transfer forward model (CAO-LDISORT), and on aerosol and bio-optical models derived from in-situ data measurements. In this paper we present, a fast tool for simultaneous retrieval of two aerosol parameters (aerosol fine-mode fraction and aerosol volume fraction), and three marine parameters (chlorophyll concentration, mineral concentration, and CDOM absorption). For inverse modelling, the algorithm uses a multidimensional unconstrained nonlinear minimization function (fminsearch) based on the Nelder-Mead method [28,29]. This method has an advantage over the other mentioned methods because it does not make use of Jacobians, and is tolerant of local minima. A more detailed description is given in Section 2.4.

\section{Data and Methods}

\subsection{MODIS Instrument}

The Moderate Resolution Imaging Spectrometer (MODIS) is one of the instruments on board the Terra and Aqua satellites [30]. It has a total of 36 spectral bands, of which 20 are reflective solar bands (RSBs) and the remaining 16 are thermal emissive bands (TEBs). Table 1 shows some of the MODIS channel specifications [30,31], including band numbers, primary use, bandwidths, center wavelength, spectral radiance, and signal-tonoise-ratio (SNR) values. In Table 1, each of the bands 3 and 4 has 20 detectors and a nadir spatial resolution of $500 \mathrm{~m}$, whereas each of the bands 8-16 has 10 detectors and a nadir spatial resolution of $1 \mathrm{~km}$. Xiong and Barnes [30] discussed the MODIS radiometric calibration procedure, including pre-launch and in-orbit calibration, in-orbit monitoring of detector response and noise characterization, and solar diffuser degradation of the MODIS instrument. They concluded that for both the RSBs and TEBs the overall inorbit performance of the instrument is satisfactory, and they identified less than 10 out of 490 detectors to be either noisy or inoperable. For working detectors the MODIS L1B algorithm converts the digital response from the sensors to TOA reflectance factors for the RSBs and in-band spectral radiances for both the RSBs and TEBs. For non-functional or noisy detectors the L1B algorithm uses interpolation from the nearest adjacent working detectors to derive the values. For a typical scene the instrument calibration accuracy requirements are $\pm 2 \%$ for RSB reflectance factors and $\pm 5 \%$ for the RSB radiance product. 
Table 1. MODIS channel specifications.

\begin{tabular}{lccccc}
\hline Primary Use & Band & $\begin{array}{c}\text { Bandwidth } \\
(\mathbf{n m})\end{array}$ & $\begin{array}{c}\text { Center } \\
\text { Wavelength }(\mathbf{n m})\end{array}$ & $\begin{array}{c}\text { Spectral } \\
\text { Radiance }\end{array}$ & $\begin{array}{c}\text { Required } \\
\text { SNR }\end{array}$ \\
\hline Land, cloud, & 3 & $459-479$ & 465.6 & 35.3 & 243 \\
aerosol properties & 4 & $545-565$ & 553.6 & 29.0 & 228 \\
\hline & 8 & $405-420$ & 411.3 & 44.9 & 880 \\
& 9 & $438-448$ & 442.0 & 41.9 & 838 \\
& 10 & $483-493$ & 486.9 & 32.1 & 802 \\
Ocean color, & 11 & $526-536$ & 529.6 & 27.9 & 754 \\
phytoplankton, & 12 & $546-556$ & 546.8 & 21.0 & 750 \\
biogeochemistry & 13 & $662-672$ & 665.5 & 9.5 & 910 \\
& 14 & $673-683$ & 676.8 & 8.7 & 1087 \\
& 15 & $743-753$ & 746.4 & 10.2 & 586 \\
& 16 & $862-877$ & 866.2 & 6.2 & 516 \\
\hline
\end{tabular}

${ }^{1}\left(\mathrm{~W} \mathrm{~m}{ }^{-2} \mathrm{sr}^{-1} \mu \mathrm{m}^{-1}\right)$.

\subsection{Inherent Optical Properties}

\subsubsection{Atmospheric Aerosol Model}

The inherent aerosol optical properties (volume fraction of fine-mode aerosol particles and aerosol volume fraction) used as input in AccuRT $[32,33]$ forward RT algorithm were obtained from AERONET [34,35] and were derived based on a bi-modal log-normal volume size distribution given by [36]

$$
v(r)=\frac{d V(r)}{d r}=\frac{1}{r} \frac{d V(\ln r)}{d \ln r}=\sum_{i=1}^{2} \frac{V_{i}}{\sqrt{2 \pi \sigma_{i}}} \frac{1}{r} \exp \left[-\left(\frac{\ln r-\ln r_{v i}}{\sqrt{2} \sigma_{i}}\right)^{2}\right],
$$

where $r$ gives varying radii the particles can have in the distribution, the subscript $i$ represents the mode (fine or coarse), $V_{i}$ is the total volume of particles associated with mode $i, r_{v i}$ is the mode radius or volume geometric mean radius, and $\sigma_{i}$ is the geometric standard deviation. In terms of the number density, Equation (1) becomes

$$
n(r)=\frac{d N(r)}{d r}=\frac{1}{r} \frac{d N(\ln r)}{d \ln r}=\sum_{i=1}^{2} \frac{N_{i}}{\sqrt{2 \pi \sigma_{i}}} \frac{1}{r} \exp \left[-\left(\frac{\ln r-\ln r_{n i}}{\sqrt{2} \sigma_{i}}\right)^{2}\right],
$$

where $N_{i}$ is the number of particles and $r_{n i}$ is the volume geometric mean (or mode) radius.

According to Ahmad et al. [36], $N_{i}$ and $r_{n i}$ in Equation (2) are, respectively related to $V_{i}$ and $r_{v i}$ in Equation (1) as follows:

$$
\begin{array}{r}
\ln r_{n i}=\ln r_{v i}-3 \sigma_{i}^{2}, \\
N_{i}=\frac{V_{i}}{\frac{4}{3} \pi r_{n i}^{3}} \exp \left(-4.5 \sigma_{i}^{2}\right) .
\end{array}
$$

Since

$$
\int_{0}^{\infty} \frac{d r}{\sqrt{2 \pi} \sigma} \frac{1}{r} \exp \left[-\left(\frac{\ln r-\ln r_{v i}}{\sqrt{2} \sigma_{i}}\right)^{2}\right]=1,
$$

integration over all sizes for both modes in Equations (1) and (2), yields

$$
\begin{gathered}
\int_{0}^{\infty} v(r) d r=V_{1}+V_{2}=V_{T} \\
\int_{0}^{\infty} n(r) d r=N_{1}+N_{2}=N_{T} .
\end{gathered}
$$


If we let subscript $i=f$ denote the fine mode, and the subscript $i=c$ to denote the coarse mode, then Equation (5a) becomes $V_{T}=V_{f}+V_{c}$. Hence the volume fraction of fine-mode particles is given by $f=V_{f} / V_{T}$.

\subsubsection{Bio-Optical Model}

In the AccuRT algorithm, the inherent optical properties (chlorophyll concentration $(\mathrm{CHL})$, mineral particle concentration (MIN), and absorption by CDOM $\left(\alpha_{\mathrm{CDOM}}(443)\right)$ are adopted from the Coast Colour Round Robin (CCRR) [37] bio-optical model. The model has 3 input parameters: CHL, MIN, and $\alpha_{\mathrm{CDOM}}(443)$. According to Babin et al. [38], the absorption coefficient for mineral particles at $443 \mathrm{~nm}$ and its spectral variation are given by

$$
\begin{gathered}
\alpha_{\mathrm{MIN}}(443)=0.041 \times \mathrm{MIN}, \\
\alpha_{\mathrm{MIN}}(\lambda)=\alpha_{\mathrm{MIN}}(443) \exp [-0.0123(\lambda-443)] .
\end{gathered}
$$

The absorption coefficient for pigmented (algal) particles is given by [39]

$$
\alpha_{\text {pig }}(\lambda)=A_{\phi}(\lambda) \times[\mathrm{CHL}]^{E_{\phi}(\lambda)} .
$$

Here $A_{\phi}(\lambda)$ and $E_{\phi}(\lambda)$ are given by Bricaud et al. [39], and [CHL] is the chlorophyll concentration. The spectral variation of the CDOM absorption coefficient is given by [40]

$$
\alpha_{\mathrm{CDOM}}(\lambda)=\alpha_{\mathrm{CDOM}}(443) \times \exp [-0.0176(\lambda-443)] .
$$

The sum of Equations (7)-(9) gives the total absorption coefficient $\alpha_{t o t}(\lambda)$ due to water impurities

$$
\alpha_{\text {tot }}(\lambda)=\alpha_{\text {pig }}(\lambda)+\alpha_{\mathrm{MIN}}(\lambda)+\alpha_{\mathrm{CDOM}}(\lambda) .
$$

It should be noted that $\alpha_{\mathrm{MIN}}(\lambda)$ in Equation (10) caters also for non-algae particles whose absorption does not covary with that of algae particles. The scattering coefficient at $555 \mathrm{~nm}$ is given by [38]

$$
\beta_{\mathrm{MIN}}(555)=0.51 \times \mathrm{MIN},
$$

and the spectral variation of the attenuation coefficient is

$$
\gamma_{\mathrm{MIN}}(\lambda)=\gamma_{\mathrm{MIN}}(555) \times\left(\lambda / \lambda_{0}\right)^{-c} ; \quad c=0.3749, \quad \lambda_{0}=555 \mathrm{~nm},
$$

where $\gamma_{\mathrm{MIN}}(555)=\alpha_{\mathrm{MIN}}(555)+\beta_{\mathrm{MIN}}(555)$.

The spectral variation of scattering coefficient for mineral particles follows from

$$
\beta_{\mathrm{MIN}}(\lambda)=\gamma_{\mathrm{MIN}}(\lambda)-\alpha_{\mathrm{MIN}}(\lambda) .
$$

According to Loise and Morel [41], the attenuation coefficient for pigmented particles at $660 \mathrm{~nm}$ wavelength is given by

$$
\gamma_{\text {pig }}(660)=\gamma_{0} \times[\mathrm{CHL}]^{\eta} ; \quad \gamma_{0}=0.407, \quad \eta=0.795,
$$

and its spectral variation is given by [42]

$$
\gamma_{\text {pig }}(\lambda)=\gamma_{\text {pig }}(660) \times(\lambda / 660)^{v},
$$

where

$$
v= \begin{cases}0.5 \times\left[\log _{10} \mathrm{CHL}-0.3\right] & 0.02<\mathrm{CHL}<2.0 \\ 0 & \mathrm{CHL}>2.0 .\end{cases}
$$


The spectral variation of scattering coefficient for pigmented particles is the difference between Equations (15) and (8)

$$
\beta_{\text {pig }}(\lambda)=\gamma_{\text {pig }}(\lambda)-\alpha_{\text {pig }}(\lambda)
$$

The sum of Equations (13) and (17) gives the scattering coefficient due to water impurities

$$
\beta_{\text {tot }}(\lambda)=\beta_{\text {MIN }}(\lambda)+\beta_{\text {pig }}(\lambda) .
$$

\subsection{Radial Basis Function Neural Network (RBF-NN)-Training and Evaluation}

\subsubsection{Radial Basis Function Neural Network}

The Radial Basis Function Neural Network (RBF-NN), first proposed by Broomhead and Lowe [43], consists of three main parts, namely an input layer, hidden layers, and an output layer $[44,45]$, and it employs radial basis functions (RBFs) as activation functions. The RBF's basic parameters are the center and width, and their response decreases (or increases) monotonically with distance from a central point [44]. There are two hidden layers of the RBF-NN, namely a RBF layer and a linear layer. The output $O_{1 i}$ from the first hidden layer (the RBF layer) is given by

$$
O_{1 i}=\exp \left[-\left(\left(x_{1 i}-w_{1 i}\right) b_{1}\right)^{2}\right]
$$

where $x_{1 i}, w_{1 i}$, and $b_{1}$ are the input, weight, and bias, respectively, of the RBF layer. The RBF layer is followed by the second hidden layer

$$
\mathrm{O}_{2 i}=w_{L i} x_{2 i}+b_{2 i}
$$

where $w_{L i}, x_{2 i}$, and $b_{2 i}$ are the weight, input, and bias of the linear layer, and $O_{2 i}$ is the final total output of the RBF-NN. If there are are $N_{p}$ input parameters, Equation (19) for the first hidden layer becomes

$$
O_{1 i}=\exp \left[-b_{1}^{2} \sum_{k=1}^{N_{p}}\left(w_{1 k}-x_{1 k}\right)^{2}\right] \text {. }
$$

Replacing $x_{2 i}$ in Equation (20) by the output $O_{1 i}$ from the first hidden layer in Equation (21), which is the input to the second hidden layer (the linear layer), one obtains

$$
O_{2 i}=w_{L i} \exp \left[-b_{1}^{2} \sum_{k=1}^{N_{p}}\left(w_{1 k}-x_{1 k}\right)^{2}\right]+b_{2 i} .
$$

If there are $N$ neurons, the $i^{\text {th }}$ output of the RBF-NN becomes

$$
O_{2 i}=\sum_{j=1}^{N} w_{L i j} \exp \left[-b_{1}^{2} \sum_{k=1}^{N_{p}}\left(w_{1 j k}-x_{1 k}\right)^{2}\right]+b_{2 i} .
$$

If we set $a_{i j}=w_{L i j}, b=b_{1}, d_{i}=b_{2 i}, c_{j k}=w_{1 j k}, p_{k}=x_{1 k}, R_{i}=O_{2 i}$, Equation (23) simplifies to

$$
R_{i}=\sum_{j=1}^{N} a_{i j} \exp \left[-b^{2} \sum_{k=1}^{N_{p}}\left(c_{j k}-p_{k}\right)^{2}\right]+d_{i},
$$

where $N_{p}$ is the total number of input/retrieval parameters, the $p_{k}$ 's are input/retrieval parameters (chlorophyll concentration, mineral concentration, CDOM absorption, aerosol fine-mode fraction, and aerosol volume fraction), and $a_{i j}, b, c_{j k}$, and $d_{i}$ are coefficients to be optimized by training the RBF-NN. The output parameters $R_{i}$ are TOA radiances in the MODIS channels at 412, 442, 487, 530, 554, 666, 746, and $866 \mathrm{~nm}$. Each term $j=1,2, \ldots, N$ 
in the outer sum in Equation (24) is referred to as a neuron, so that $N$ is the actual number of neurons after optimisation.

\subsubsection{Training and Evaluation}

In order to obtain accurate results from Equation (24) it is vital to have adequate input data for the RBF-NN training. To train and evaluate the RBF-NN we chose input data relevant for the coastal waters around Røst $\left(67.79^{\circ} \mathrm{N}, 12.01^{\circ} \mathrm{E}\right)$, Norway, whose location is shown in Figure 1. At this site there are in-situ measurements of marine parameters (chlorophyll concentration, mineral concentration, and CDOM absorption), and the site is not too far from Andenes $\left(69.28^{\circ} \mathrm{N}, 16.01^{\circ} \mathrm{E}\right)$, Norway, where the Aerosol Robotic Network (AERONET) has provided measurements of aerosol properties for more than 10 years. Marine in-situ measurements at Røst (Nima et al. [46]) have provided values of the chlorophyll concentration, total suspended matter (TSM), and CDOM absorption. The chlorophyll concentration was obtained from collected water samples using High Pressure Liquid Chromatography (HPLC) based on the method of Jeffrey and Mantoura et al. [47]. The CDOM absorption was determined by converting absorbance spectra recorded by a dual-beam Shimadzu spectrophotometer (UV-1800) of filtered water samples. TSM was obtained by taking the difference between the weights of Whatman $47 \mathrm{~nm}$ GF/F filter after and before filtration. To obtain the concentration of mineral particles, the chlorophyll concentration was subtracted from the TSM.

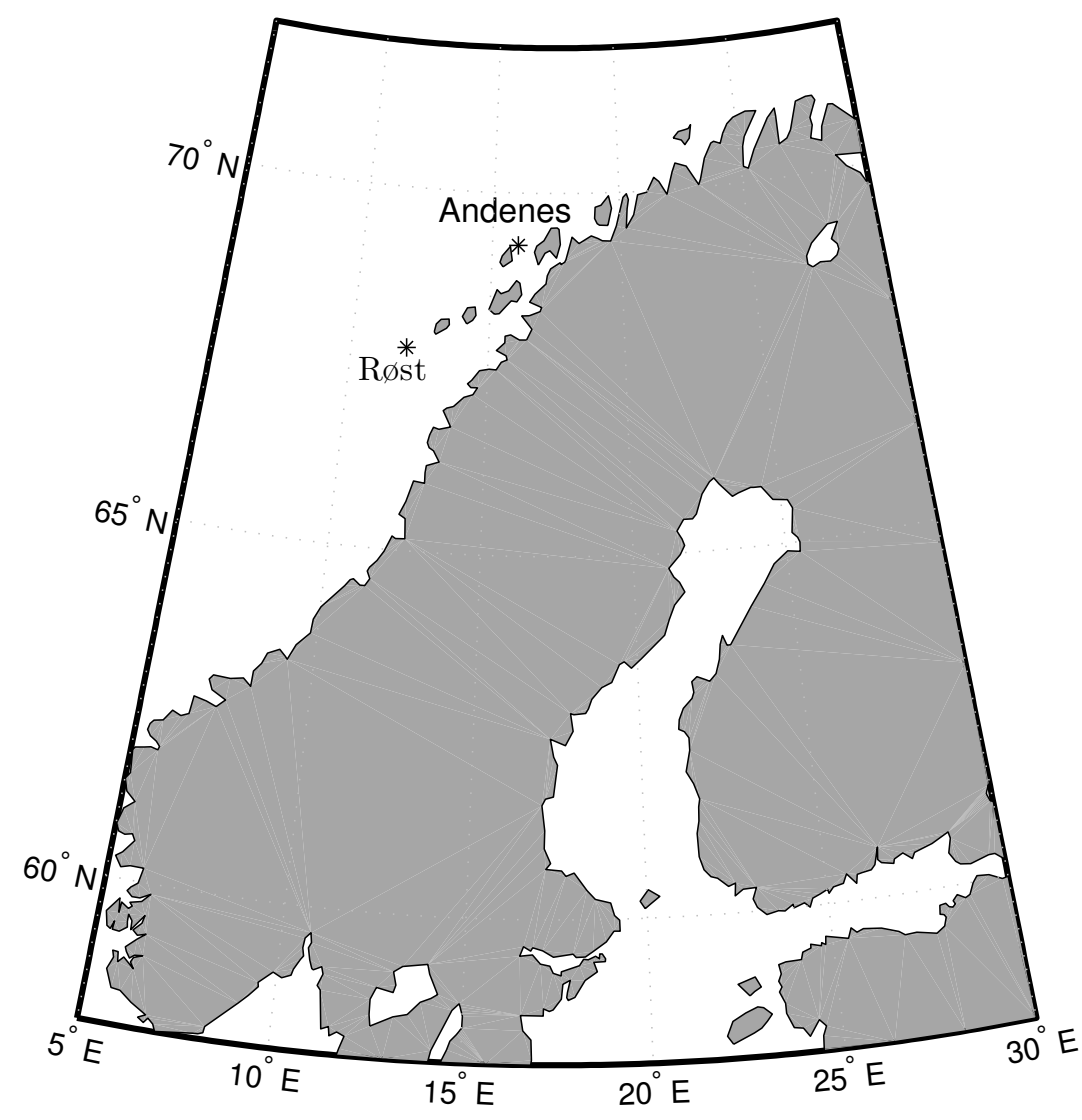

Figure 1. Location of the two sites, Røst and Andenes.

Aerosol parameter values for Andenes were downloaded from AERONET to obtain the volume concentration of fine-mode particles $\left(\mathrm{V}_{f}\left[\mu \mathrm{m}^{3} / \mu \mathrm{m}^{2}\right]\right)$, the volume concentration of coarse-mode particles $\left(\mathrm{V}_{c}\left[\mu \mathrm{m}^{3} / \mu \mathrm{m}^{2}\right]\right)$, and the total volume concentration of particles $\left(V_{T}\left[\mu \mathrm{m}^{3} / \mu \mathrm{m}^{2}\right]\right)$. Volume concentration is the fraction of a given volume occupied (filled) by particles. In contrast to mass concentration, volume fraction is independent of the bulk 
density of the particle material. In our retrieval algorithm the volume fraction of fine-mode particles is defined as $f=\mathrm{V}_{f} / \mathrm{V}_{T}$, and the aerosol volume fraction is defined as $\mathrm{V}_{T}$ divided by the thickness in [ $\mu \mathrm{m}]$ of the aerosol layer, which was assumed to extend from sea level to a height of $2 \mathrm{~km}$.

The variation range of each of the marine parameters was determined by considering the values obtained from all cruise measurements around Røst and then selecting the minimum and maximum values. The minimum and maximum values of the aerosol parameters were determined by considering monthly averages of the aerosol volume fraction and the volume fraction of fine-mode particles $\left(\mathrm{V}_{f}\right)$ and then picking the smallest and largest values. The ranges used were: CDOM absorption coefficient $(0.11-0.16) \mathrm{m}^{-1}$ at $440 \mathrm{~nm}$; chlorophyll concentration $(0.7-2.0) \mathrm{mg} \mathrm{m}^{-3}$; mineral concentration $(0.2-0.7) \mathrm{g} \mathrm{m}^{-3}$; aerosol volume fraction $\left(3.75 \times 10^{-12}-3.24 \times 10^{-11}\right)$; and volume fraction of fine-mode particles $\left(\mathrm{V}_{f}\right)(0.80-0.84)$.

After determining the range of each of the five input/retrieval parameters, we used a random number generator to provide 10,000 different random sets of parameter values. These 10,000 sets of parameter values were used as input to a well-tested RTM for a coupled atmosphere-ocean system [14,32] to simulate measured TOA radiances in the MODIS channels at 412,442, 487, 530, 554, 666, 746, and $866 \mathrm{~nm}$. In all the TOA radiance simulations we assumed the satellite sensor zenith angle to be at nadir because all the stations at which the in-situ measurements where carried out the satellite sensor zenith varies between $0.2^{\circ}$ to $1.5^{\circ}$.

To determine optimized values for the coefficients $a_{i j}, b, c_{j k}$, and $d_{i}$ in Equation (24) for the ranges of the five input/retrieval parameters given above, we used the MATLAB radial basis function 'newrb', which iteratively creates a RBF-NN by adding neurons one at a time until the mean-squared error (MSE) defined as [48,49]

$$
\mathrm{MSE}=\frac{1}{N_{S}} \sum_{i=1}^{N_{S}}\left(R_{i}^{T}-R_{i}^{P}\right)^{2},
$$

falls beneath an error goal or a actual number of neurons after optimisation $N$ in Equation (24) has been reached. Here $R_{i}^{T}$ is the target value of the TOA radiance computed by a welltested RTM for the $i$ th MODIS channel, and $R_{i}^{P}$ is the corresponding TOA radiance value predicted by the RBF-NN in Equation (24), and $N_{S}$ is the number of instrument channel used.

The call for the MATLAB function 'newrb' includes the parameters $p_{k}, R_{i}$, goal, spread, and $N$, where $p_{k}\left(k=1,2, \ldots, N_{p}\right)$ are different sets of the five input/retrieval parameters and $R_{i}$ are corresponding sets of RBF-NN predicted TOA radiance values, whereas goal, spread, and $N$ are design parameters. As noted above, $N$ is the actual number of neurons after optimisation in Equation (24). Further, goal is equal to the mean-squared error MSE, and spread is equal to the width of the RBF-NN. We used $90 \%$ of the 10,000 sets of input parameters (9000 parameter sets) for training and the remaining 10\% (1000 parameter sets) for validation. After testing different combinations of values for goal, spread, and $N$, we found the combination of settings goal $=0$, spread $=1.5$, and $N=300$ to give very accurate results. Figure 2 shows a comparison between the TOA radiances obtained from the RBF-NN and the RTM. The correlation coefficients between the two models for SZAs $45^{\circ}, 53^{\circ}, 63^{\circ}$, and $75^{\circ}$ are $0.99999996,0.99999910,0.99999967$, and 0.99999984 , respectively, with average deviations of $0.011 \%, 0.047 \%, 0.029 \%$, and $0.015 \%$, respectively. The RBF-NN did not achieve the targeted value of goal $=0$, but at the point of termination with $N=300$ the value was goal $=1.0 \times 10^{-7}$. In addition to predicting the TOA radiances very well, the RBF-NN is faster than the RTM by a factor of 200. 


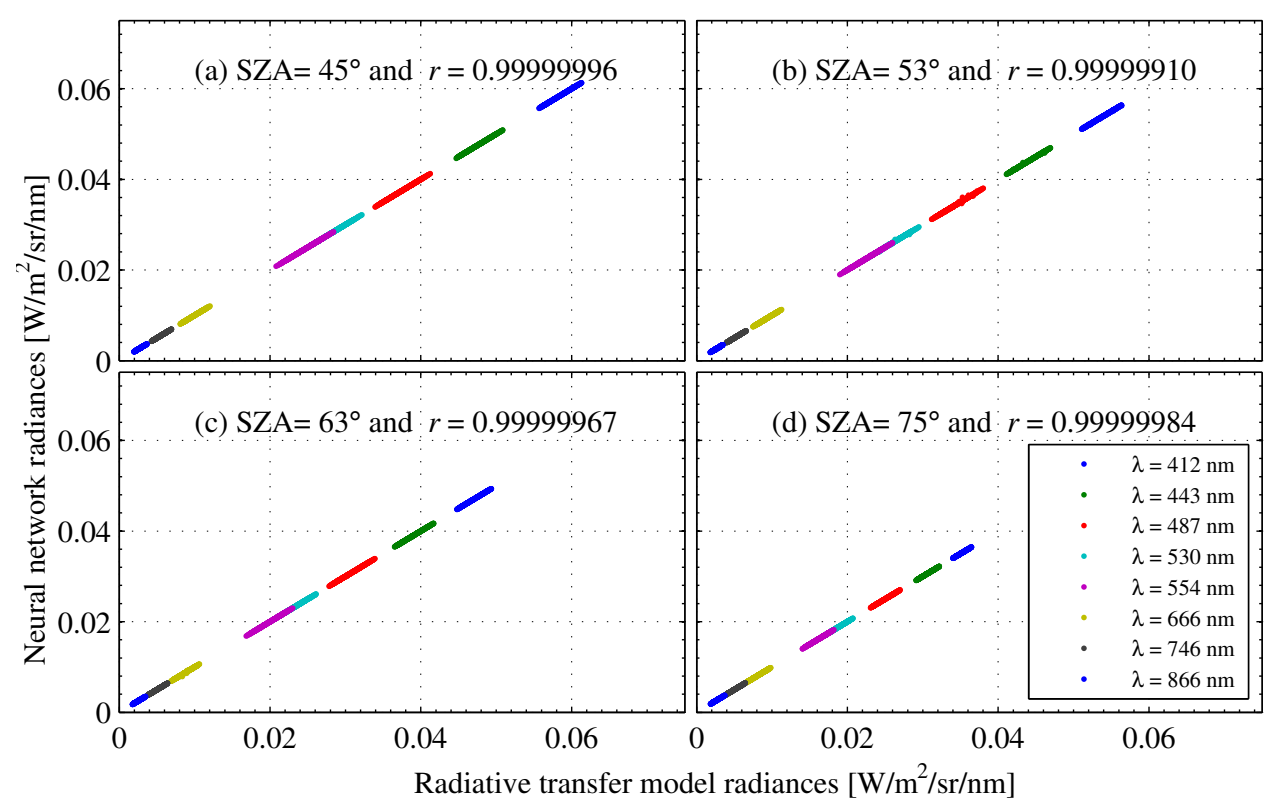

Figure 2. Comparison between radiances obtained from the RBF-NN and those obtained from a well-tested radiative transfer model (RTM) for a coupled atmosphere-ocean system (viewing angle $\left.\theta=0^{\circ}\right)$. Note that in graphs $(\mathbf{a}-\mathbf{d})$ both the shortest wavelength $(412 \mathrm{~nm})$ and the longest wavelength $(866 \mathrm{~nm})$ are represented by the blue color, and that the higher radiance values corresponds to $412 \mathrm{~nm}$.

\subsection{Inverse Method for Retrieval of Atmosphere-Water Parameters from TOA Radiances}

As explained above, our inverse algorithm is based on a multidimensional unconstrained nonlinear minimization MATLAB function (fminsearch) in accordance with a method due to Nelder-Mead [28,29]. The aim of the Nelder and Mead [28] method is to minimize a scalar-valued nonlinear function of several real variables using function values only. The following four scalar coefficients of reflection $(\rho>0)$, expansion $(\chi>1, \rho)$, contraction $(0<\gamma<1)$, and shrinkage $(0<\sigma<1)$ must be specified in order to implement the method. The Nelder-Mead search method maintains a non-degenerate simplex of $n+1$ points for $n$-dimensional vectors $x$. The algorithm starts by adding $5 \%$ to each component of the initial guess $x_{0}$, and the new generated vectors $x_{0}(i)$ become the elements of the new simplex in addition to $x_{0}$. If $x_{0}(i)=0$, then $x_{0}(i)$ is set to 0.00025 , and the algorithm then follows the procedure below until the diameter of the simplex is less than a specified tolerance.

(i) Let $x(i)$ denote the list of points in the current simplex, $i=1, \ldots, n+1$. Then the algorithm orders the points in the simplex from the lowest function value $f(x(1))$ to the highest function value $f(x(n+1))$, and at each step in the iteration the algorithm discards the current worst point $x(n+1)$ and accepts another point in the simplex. Or, in case of step (v) below it changes all $n$ points with values above $f(x(1))$.

(ii) To generate a reflection point, the algorithm generates a point $r=2 m-x(n+1)$, where $m=\sum x(i) / n, i=1, \ldots, n$, and then calculates $f(r)$. If $f(x(1)) \leq f(r)<$ $f(x(n))$, then the algorithm accepts $r$ and terminates the iteration.

(iii) To generate an expansion point for the case in which $f(r)<f(x(1))$, the algorithm calculates an expansion point $s$, given by $s=m+2(m-x(n+1))$, and then computes $f(s)$. If $f(s)<f(r)$, the algorithm accepts $s$ and terminates the iteration. Otherwise, it accepts $r$ and returns to procedure step (ii).

(iv) If $f(r) \geq f(x(n))$, the algorithm performs a contraction between $m$ and the better of $x(n+1)$ and $r$. Case I: If $f(r)<f(x(n+1))$ (i.e., $r$ is better than $x(n+1))$, the algorithm calculates $c=m+(r-m) / 2$, and then computes $f(c)$. If $f(c)<f(r)$, it accepts $c$ and terminates the iteration. Otherwise, it continues with step (v). Case II: If $f(r) \geq f(x(n+1))$, it calculates $c c=m+(x(n+1)-m) / 2$ and com- 
putes $f(c c)$. If $f(c c)<f(x(n+1))$, it accepts $c c$ and terminates the iteration. Otherwise, it continues with step (v).

(v) To generate a shrinkage point, the algorithm calculates the $n$ points $v(i)=x(1)+(x(i)-x(1)) / 2$ and computes $f(v(i)), i=2, \ldots, n+1$. The simplex at the next iteration is $x(1), v(2), \ldots, v(n+1)$. The iteration continues until the set criterion is fulfilled

In our algorithm the initial guess for the components of the vector $x_{0}$ was the average values of the input parameters.

\section{Results and Discussion}

To validate the performance of our inverse algorithm described in Section 2.4, we compared the two aerosol and the three marine parameters that were used as inputs to the RTM for generating computed TOA radiances for the MODIS channels with the corresponding retrieved parameters.

To test for robustness we considered two cases: (i) low and high sun without white Gaussian noise added to the computed TOA radiances and (ii) low and high sun with different levels of white noise added to the computed TOA radiances. In both cases, we used the RTM for computation of TOA radiances, and trained the RBF-NN separately for each SZA, and in the latter case, we added white Gaussian noise to the computed TOA radiances in order to check how much added white Gaussian noise the inverse algorithm would tolerate. All statistics about algorithm performance validation and robustness testing were conducted on testing data set.

For each of the five input parameters, the correlation coefficient $r_{j}(j=1,2,3,4,5)$ between input parameter number $j$ and the corresponding retrieved parameter was computed using

$$
r_{j}=\frac{\sum_{i=1}^{M}\left(p_{j, i}^{s}-\overline{p_{j}^{s}}\right)\left(p_{j, i}^{t}-\overline{p_{j}^{t}}\right)}{\left[\sum_{i=1}^{M}\left(p_{j, i}^{s}-\overline{p_{j}^{s}}\right)^{2} \sum_{i=1}^{M}\left(p_{j, i}^{t}-\overline{p_{j}^{t}}\right)^{2}\right]^{1 / 2}},
$$

where $p_{j, i}^{s}$ is the $i^{\text {th }}$ data point for input parameter number $j$ and $p_{j, i}^{t}$ is the corresponding retrieved parameter, and $M$ is the total number of data points, which is equal to the number of parameter sets used for validation, i.e., $M=10,000$. The average values in Equation (26) are given by

$$
\overline{p_{j}^{s}}=\frac{1}{M} \sum_{i=1}^{M} p_{j, i}^{s} ; \overline{p_{j}^{t}}=\frac{1}{M} \sum_{i=1}^{M} p_{j, i}^{t} .
$$

At Røst local noon solar zenith angles (SZAs) of $45^{\circ}, 53^{\circ}, 63^{\circ}$, and $75^{\circ}$ correspond to the dates of 5 June, 1 May, 1 April, and 1 March, respectively. Table 2 shows correlation between input and retrieved parameters for different solar zenith angles, and different sets of data in absence of noise. The algorithm performed well in retrieving all the five parameters in both data sets in absence of noise.

Figures 3-7 show comparisons between input parameters and retrieved parameters for different solar zenith angles, and the correlation coefficients are given in Table 2 under testing data set.

Figure 3 shows a comparison between input values and retrieved values for the CDOM absorption coefficient for different SZAs. The correlation coefficients are 0.97, 0.82, 0.72, and 0.64 for SZAs of $45^{\circ}, 53^{\circ}, 63^{\circ}$, and $75^{\circ}$, respectively.

Figure 4 shows a comparison between input values and retrieved values for the chlorophyll concentration with correlation coefficients of $0.98,0.78,0.82$, and 0.73 for SZAs of $45^{\circ}, 53^{\circ}, 63^{\circ}$, and $75^{\circ}$, respectively. It follows that the chlorophyll concentration is retrieved well, both for low and high sun. 
Table 2. Correlation coefficients between input parameters and retrieved parameters for different solar zenith angles in absence of noise.

\begin{tabular}{lllllllll}
\hline & \multicolumn{4}{c}{ Testing Data Set } & \multicolumn{3}{c}{ Training Data Set } \\
\hline & \multicolumn{4}{c}{ Solar Zenith Angle } \\
\hline Retrieved Parameter & $45^{\circ}$ & $53^{\circ}$ & $63^{\circ}$ & $75^{\circ}$ & $45^{\circ}$ & $53^{\circ}$ & $63^{\circ}$ & $75^{\circ}$ \\
\hline CDOM & 0.97 & 0.82 & 0.72 & 0.64 & 1.00 & 0.80 & 0.97 & 0.84 \\
Chlorophyll Concentration & 0.98 & 0.78 & 0.82 & 0.73 & 1.00 & 0.95 & 0.99 & 0.97 \\
Mineral Concentration & 1.00 & 0.94 & 0.93 & 0.96 & 1.00 & 0.67 & 0.96 & 0.87 \\
Aerosol fine-mode fraction & 0.82 & 0.67 & 0.93 & 0.91 & 1.00 & 0.98 & 1.00 & 1.00 \\
Aerosol volume fraction & 0.97 & 0.87 & 0.92 & 0.92 & 0.99 & 0.82 & 0.97 & 0.94 \\
\hline
\end{tabular}

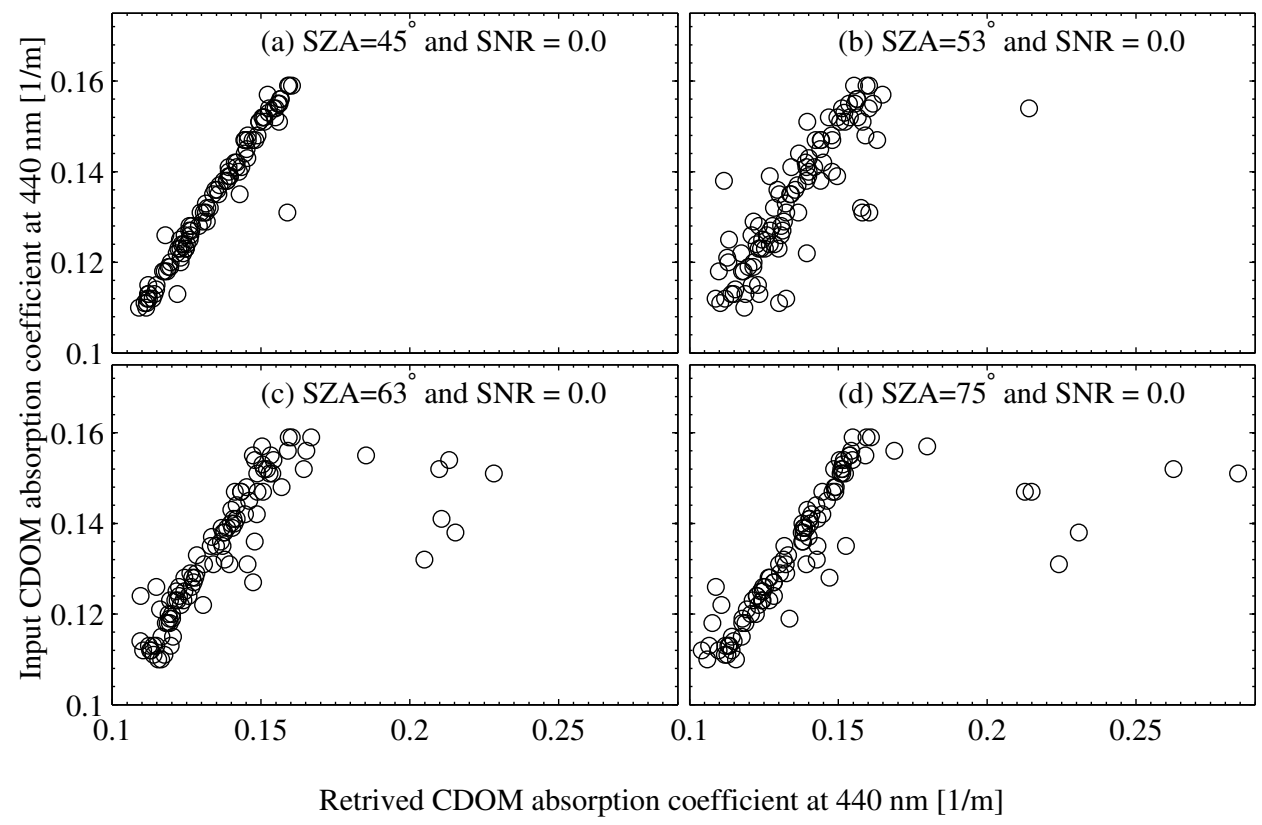

Figure 3. Comparison between input values and retrieved values for the CDOM absorption coefficient at $443 \mathrm{~nm}$ for different solar zenith angles (SZAs).

Figure 5 shows a comparison between input values and retrieved values for the mineral concentration. The correlation coefficients between input values and retrieved values are $1.00,0.94,0.93$, and 0.96 for SZAs of $45^{\circ}, 53^{\circ}, 63^{\circ}$, and $75^{\circ}$, respectively. Thus, the mineral concentration is retrieved accurately, both for low and high sun.

Figure 6 shows a comparison between input and retrieved values for the volume fraction of fine-mode aerosol particles, where the correlation coefficients between input and retrieved values are $0.82,0.67,0.93$, and 0.91 for SZAs of $45^{\circ}, 53^{\circ}, 63^{\circ}$, and $75^{\circ}$, respectively. For all four values of the SZA, we see that the retrieval algorithm predicts the volume fraction of fine-mode aerosol particles very well.

Figure 7 shows a comparison between input values and retrieved values for the aerosol volume fraction with correlation coefficients of $0.97,0.87,0.92$, and 0.92 for SZAs of $45^{\circ}$, $53^{\circ}, 63^{\circ}$, and $75^{\circ}$, respectively. For all values of the SZA, the retrieval algorithm is seen to accurately predict the aerosol volume fraction.

Figure 8 shows the effect of the SZA on the TOA radiance contribution from the ocean. The ratio between the average total TOA radiance and the average TOA radiance contribution from the ocean is seen to increase significantly (note the logarithmic scale on the vertical axis in Figure 8) with increasing SZA, implying that the oceanic contribution to the TOA radiance is reduced as the SZA is increased. This may explain why the accuracy 
of the retrieved ocean parameters (CDOM absorption and chlorophyll concentration) in Figures 3 and 4 reduced as the SZA is increased.

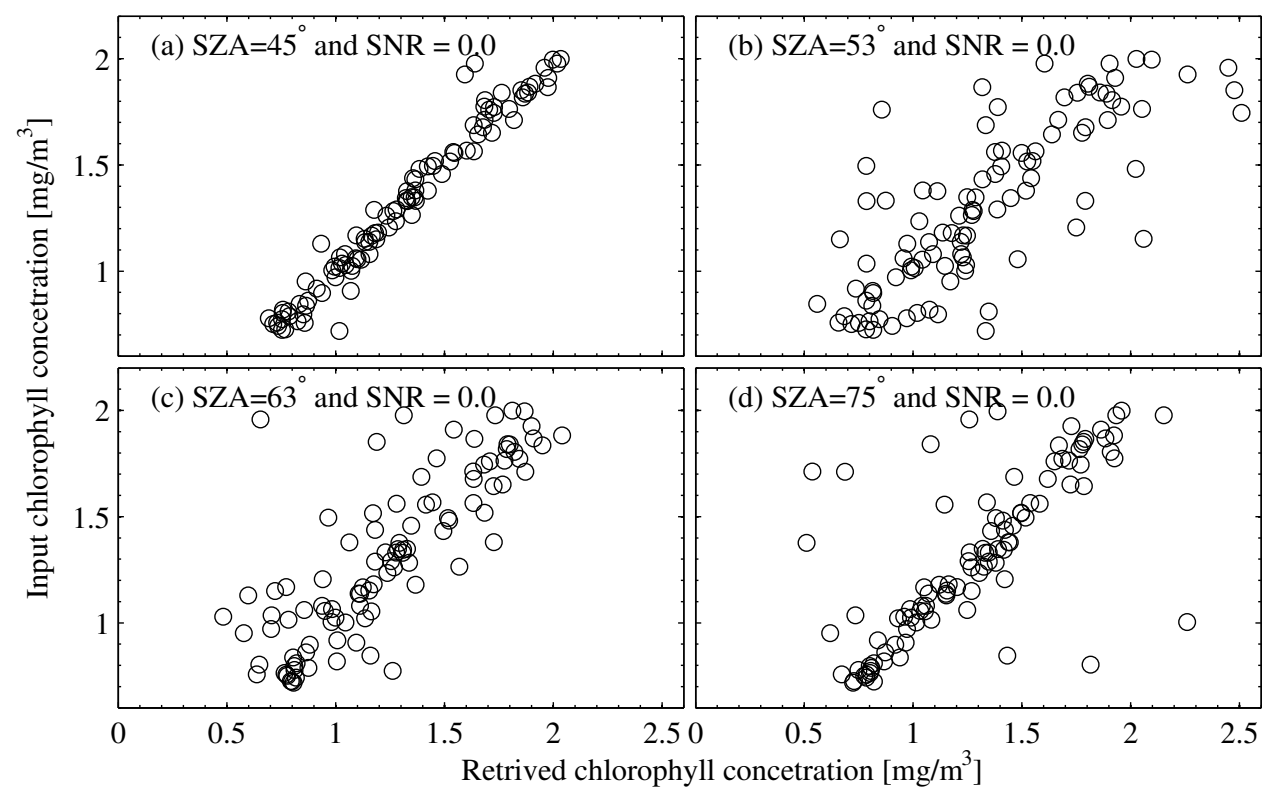

Figure 4. Comparison between input values and retrieved values for the chlorophyll concentration for different solar zenith angles (SZAs).

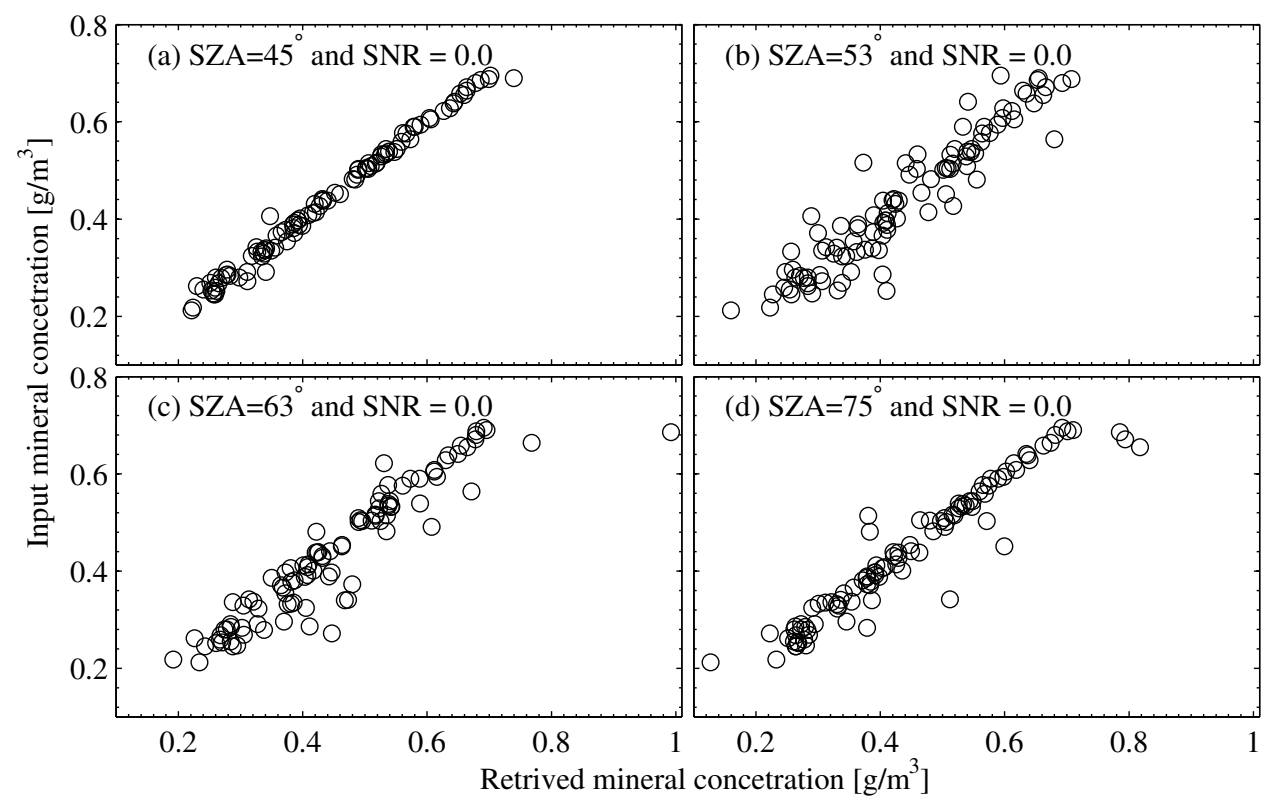

Figure 5. Comparison between input values and retrieved values for the mineral concentration for different solar zenith angles (SZAs). 


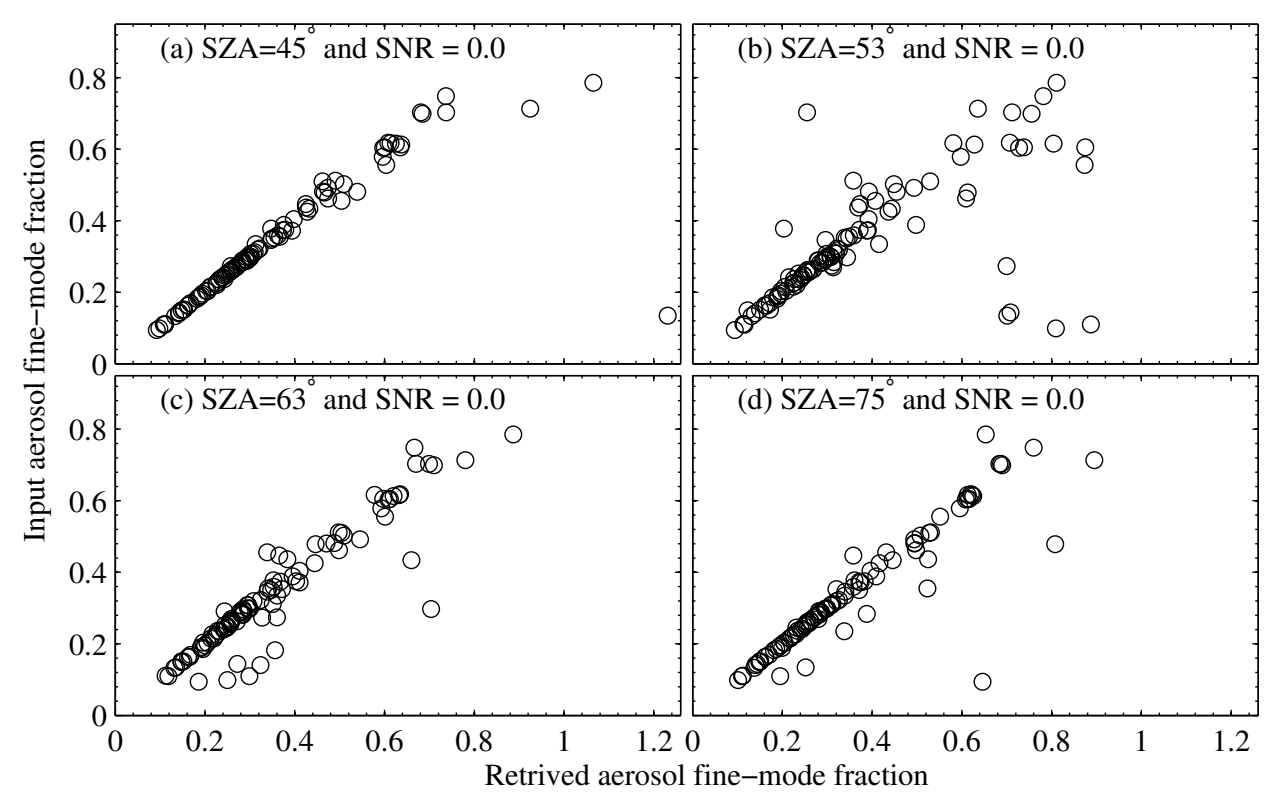

Figure 6. Comparison between input values and retrieved values for the volume fraction of fine-mode aerosol particles for different solar zenith angles (SZAs).

To test for robustness of the retrieval algorithm we introduced white Gaussian noise in all eight TOA radiance channels using the MATLAB function $\operatorname{awg} n(\mathrm{X}, \mathrm{SNR})$, where $\mathrm{X}$ is the vector signal and SNR is the signal-to-noise-ratio. Figure 9a-e show how the algorithm predicts CDOM absorption, chlorophyll concentration, mineral concentration, aerosol volume fraction, and volume fraction of fine-mode aerosol particles for four different values of the SZA and the SNR. As discussed earlier, we first generated 10,000 randomly distributed sets of the five input parameters. Then we used a well-tested forward RTM to compute TOA radiances for eight of the MODIS channels for each of the 10,000 sets of input parameters for training $(90 \%)$ and validation $(10 \%)$ of a RBF-NN. To speed up the inversion, we used TOA radiances predicted by the RBF-NN as input to the retrieval algorithm, which was based on fminsearch. We then added varying amounts of white Gaussian noise to the TOA radiances before starting the retrieval without re-training the RBF-NN. Figure 9a,b show how the algorithm retrieves the CDOM absorption coefficient at $443 \mathrm{~nm}$ and the chlorophyll concentration, respectively, for varying values of the SNR and four different SZA values. It is clearly seen that for low noise the algorithm retrieves the two parameters very well and that the performance decreases as one increases the SZA and the noise level. 


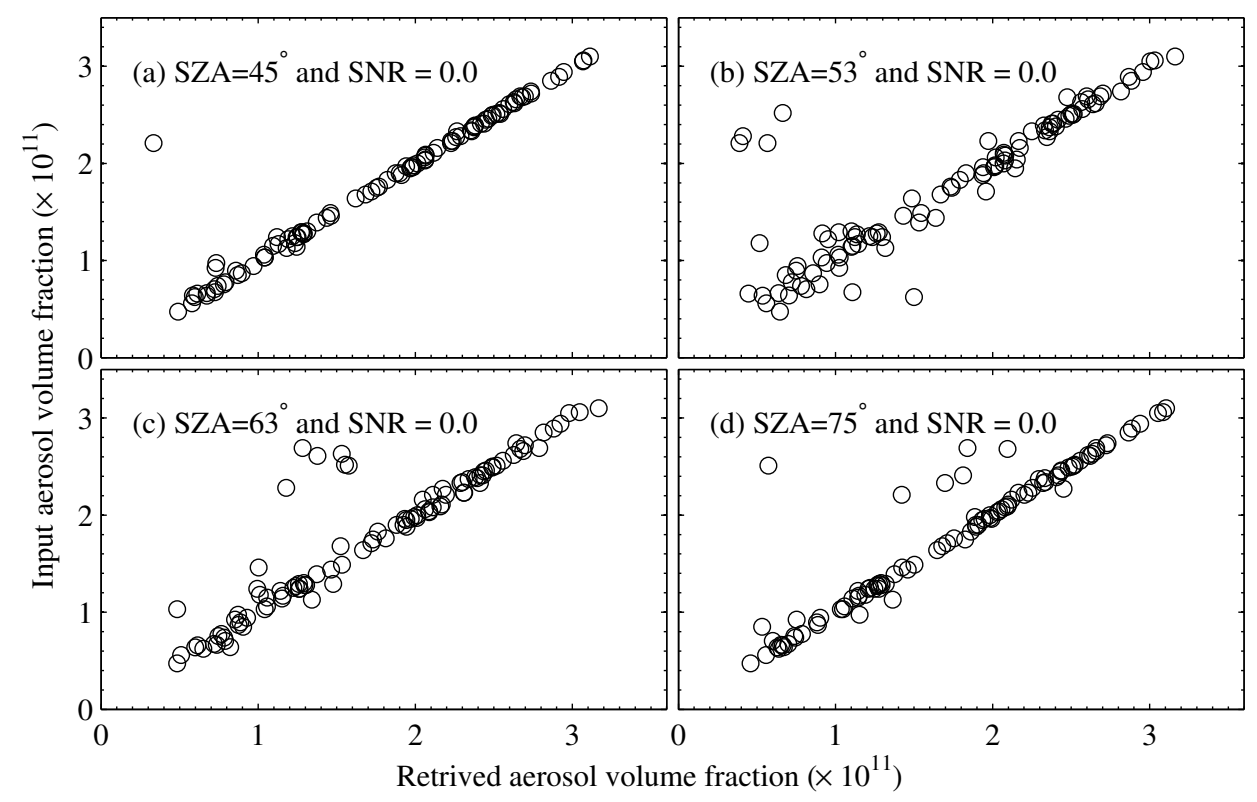

Figure 7. Comparison between input values and retrieved values for the aerosol volume fraction for different solar zenith angles (SZAs).

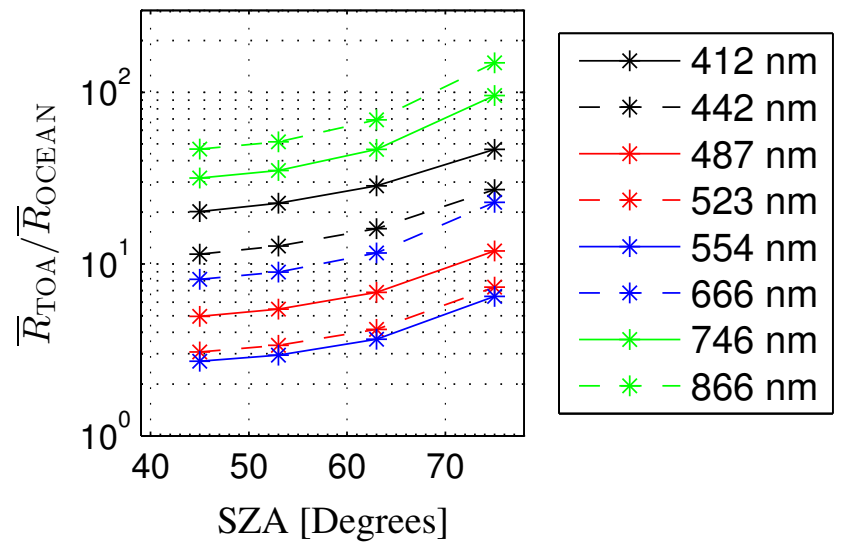

Figure 8. Effects of SZA on the TOA radiance contribution from the ocean. $\bar{R}_{\mathrm{TOA}}$ and $\bar{R}_{\mathrm{OCEAN}}$ are the average TOA radiance and average radiance from the ocean, respectively.

Figure $9 \mathrm{c}-\mathrm{e}$ show how the algorithm retrieves the mineral concentration, aerosol volume fraction, and volume fraction of fine-mode aerosol particles, respectively, for varying values of the SNR and four different SZA values. For all values of the SZA and for SNR $\geq 100$ the algorithm is seen to predict the three parameters with correlation coefficients greater than $0.88,0.77$, and 0.57 for the mineral concentration, volume fraction, and volume fraction of fine-mode aerosol particles, respectively. It follows from Figure 9 that the algorithm performance increases when the SZA or the level of white noise is reduced. 


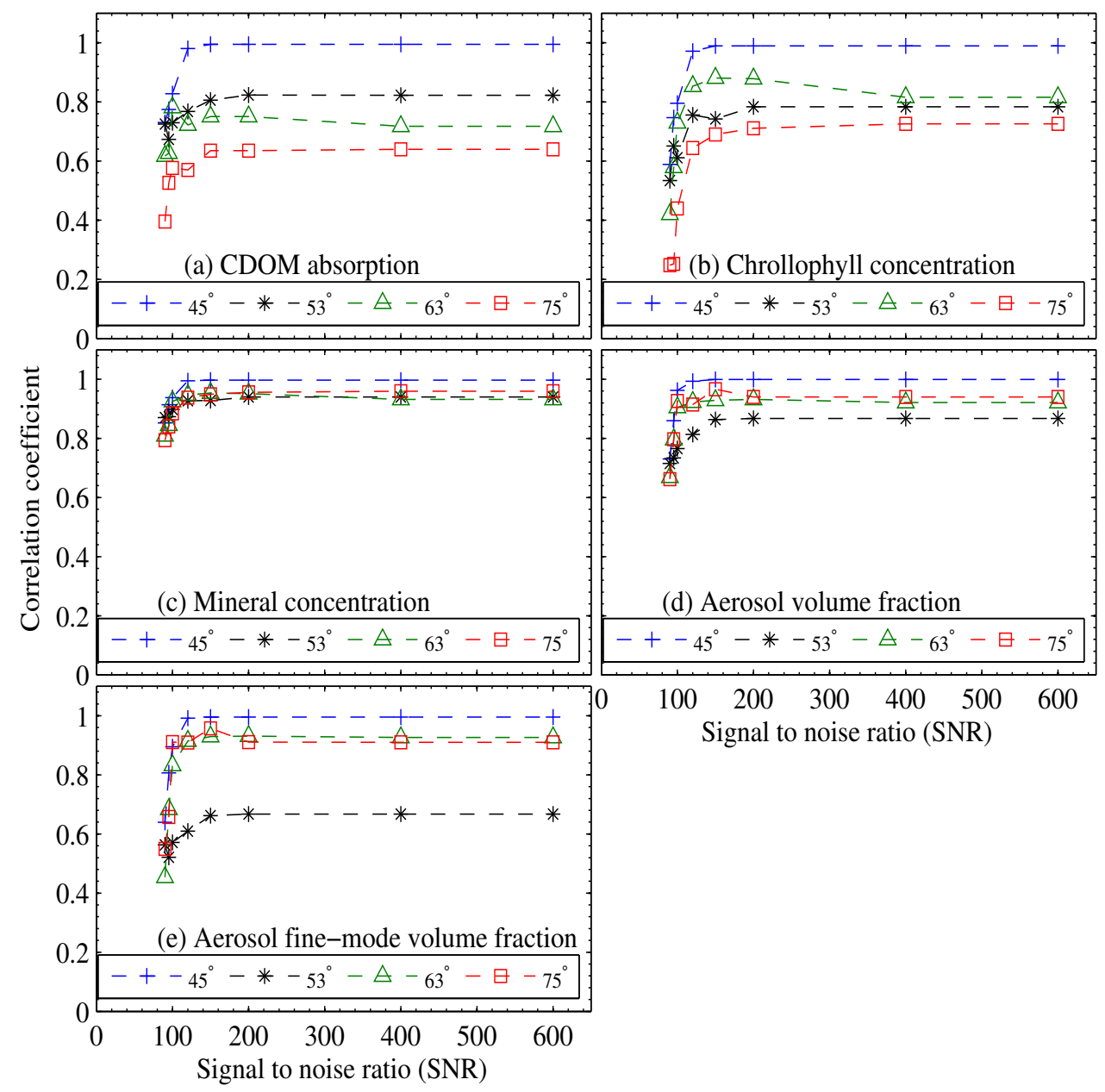

Figure 9. Effects of white Gaussian noise on the retrieved parameters.

\section{Conclusions}

We have presented a new algorithm for simultaneous retrieval of two aerosol parameters (volume fraction of fine-mode particles and aerosol volume fraction) and three marine parameters (CDOM absorption, chlorophyll concentration, and mineral concentration). We tested the performance of the new algorithm by creating a set of synthetic data and simulated the TOA radiances in 9 MODIS channels for randomly generated aerosol and marine parameter combinations. The results show that with sufficiently low noise levels our algorithm is accurate in predicting all the five parameters. For high sun $\left(\mathrm{SZA}=45^{\circ}\right.$, $53^{\circ}$, and $63^{\circ}$ ) without white noise added to the TOA radiance the algorithm predicts the CDOM absorption, chlorophyll concentration, mineral concentration, volume fraction of fine-mode aerosol particles, and aerosol volume fraction with correlation coefficients greater than $0.77,0.70,0.93,0.78$, and 0.96 , respectively. We also demonstrated that the algorithm is robust by varying the SZA between $45^{\circ}$ and $75^{\circ}$ while introducing white noise to the TOA radiance. For SNR $\geq 100$ the algorithm predicted the five parameters accurately. For SZA $>75^{\circ}$ the plane-parallel geometry used in the forward model will give inaccurate results. For such large SZA values curvature effects must be considered. This parameter retrieval technique applies to any ocean satellite sensor, though it is limited to cloud-free sky conditions. In conclusion, the algorithm is faster than RTM by a factor of 200, accurate, and robust, and can be applied to coastal waters as long as the ranges of the five retrieval parameters are known, and the noise level is low. 


\section{Final Remarks}

After this paper was finalized, important improvements have been made on atmospheric correction and retrieval of aerosol and marine parameters in turbid waters [50,51]. The improved approach described in [50] is based on the use of multilayer neural networks, and in [51] a new OC-SMART platform is described for analysis of data collected by many different existing and possible future multi-spectral and hyper-spectral satellite ocean color sensors from US, EU, Korea, Japan, and China. Also, a new cloud mask was recently developed [52], which, compared to previous cloud masks, does not rely on thresholds, needs fewer satellite channels, has superior performance during winter seasons in mid-latitude areas, and can easily be applied to different sensors.

Author Contributions: Data curation, T.S., D.M., N.S., K.S. and J.J.S.; formal analysis, T.S. and B.H.; funding acquisition, J.J.S. and Ø.F. ; investigation, T.S., B.H., Ø.F., K.S. and J.J.S.; supervision, Ø.F. and J.J.S.; writing—review and editing, T.S. and J.J.S. All authors have read and agreed to the published version of the manuscript.

Funding: This research was funded by Norwegian Research Council grant number 212019.

Institutional Review Board Statement: Not applicable.

Informed Consent Statement: Not applicable.

Data Availability Statement: Not applicable.

Conflicts of Interest: The authors declare no conflict of interest.

\section{References}

1. Gordon, H.R.; Wang., M. Retrieval of water-leaving radiance and aerosol optical thickness over the oceans with SeaWiFS: A preliminary algorithm. Appl. Opt. 1994, 33, 443-452. [CrossRef] [PubMed]

2. Gordon, H.R. Atmospheric correction of ocean color imagery in the Earth Observing System era. J. Geophy. Res. 1997, 102, 17081-17106. [CrossRef]

3. Antoine, D.; Morel, A. A multiple scattering algorithm for atmospheric correction of remotely sensed ocean colour (MERIS instrument): Principle and implementation for atmospheres carrying various aerosols including absorbing ones. Int. J. Remote Sens. 1999, 20, 1875-1916. [CrossRef]

4. Carder, K.L.; Chen, F.R.; Cannizzaro, J.P.; Campbell, J.W.; Mitchell, B.G. Performance of the MODIS semi-analytical ocean color algorithm for chlorophyll-a. Adv. Space Res. 2004, 33, 1152-1159. [CrossRef]

5. Doerffer, R.; Fischer, J. Concentrations of chlorophyll, suspended matter, and gelbstoff in case II waters derived from satellite coastal zone color scanner data with inverse modeling methods. J. Geophys. Res. 1994, 99, 7457-7466. [CrossRef]

6. Fischer, J.; Doerffer, R. An inverse technique for remote detection of suspended matter, phytoplankton and yellow substance from CZCS measurements. Adv. Space Res. 1987, 7, 21-26. [CrossRef]

7. Siegel, D.A.; Wang, M.; Maritorena, S.; Robinson, W. Atmospheric Correction of Satellite Ocean Color Imagery: The Black Pixel Assumption. Appl. Opt. 2000, 39, 3582-3591. [CrossRef] [PubMed]

8. Hovis, W.A.; Clark, D.K.; Anderson, F.; Austin, R.W.; Wilson, W.H.; Baker, E.T.; Ball, D.; Gordon, H.R.; Mueller, J.L.; El-Sayed, S.Z.; et al. Nimbus-7 Coastal Zone Color Scanner: System Description and Initial Imagery. Science 1980, 210, 60-63.

9. Chomko, R.M.; Gordon, H.R. Atmospheric correction of ocean color imagery: Use of the Junge power-law aerosol size distribution with variable refractive index to handle aerosol absorption. Appl. Opt. 1998, 37, 5560-5572. [CrossRef]

10. Gordon, H.R.; Du, T.; Zhang, T. Remote sensing of ocean color and aerosol properties: Resolving the issue of aerosol absorption. Appl. Opt. 1997, 36, 8670-8684. [CrossRef]

11. Frette, Ø.; Stamnes, J.J.; Stamnes, K. Optical Remote Sensing of Marine Constituents in Coastal Waters: A Feasibility Study. Appl. Opt. 1998, 37, 8318-8326. [CrossRef] [PubMed]

12. Stamnes, K.; Li, W.; Yan, B.; Eide, H.; Barnard, A.; Pegau, W.S.; Stamnes, J.J. Accurate and self-consistent ocean Color Algorithm: Simultaneous Retrieval of Aerosol Optical Properties and Chlorophyll Concentrations. Appl. Opt. 2003, 42, 939-951. [CrossRef] [PubMed]

13. Gordon, H.; Brown, O.B.; Evans, R.H.; Brown, J.W.; Smith, R.C.; Baker, K.S.; Clark, D.K. A semianalytic radiance model of ocean color. J. Geophys. Res. 1988, 93, 10909-10924. [CrossRef]

14. Jin, Z.; Stamnes, K. Radiative transfer in nonuniformly refracting layered media: atmosphere-ocean system. Appl. Opt. 1994, 33, 431-442. [CrossRef]

15. Yan, B.; Stamnes, K.; Li, W.; Chen, B.; Stamnes, J.J.; Tsay, S.C. Pitfalls in atmospheric correction of ocean color imagery: How should aerosol optical properties be computed? Appl. Opt. 2002, 41, 412-423. [CrossRef] [PubMed] 
16. Chomko, R.M.; Gordon, H.R.; Maritorena, S.; Siegel, D.A. Simultaneous retrieval of oceanic and atmospheric parameters for ocean color imagery by spectral optimization: A validation. Remote Sens. Environ. 2003, 84, 208-220. [CrossRef]

17. Garver, S.A.; Siegel, D.A. Inherent optical property inversion of ocean color spectra and its biogeochemical interpretation: 1. Time series from the Sargasso Sea. J. Geophys. Res. 1997, 102, 18607-18625. [CrossRef]

18. Steinmetz, F.; Deschamps, P.Y.; Ramon, D. Atmospheric correction in presence of sun glint: Application to MERIS. Opt. Express 2011, 19, 9783-9800. [CrossRef]

19. Li, W.; Stamnes, K.; Spurr, R.; Stamnes, J.J. Simultaneous retrieval of aerosol and ocean properties by optimal estimation: SeaWiFS case studies for the Santa Barbara Channel. Int. J. Remote Sens. 2008, 29, 5689-5698. [CrossRef]

20. Spurr, R.; Stamnes, K.; Eide, H.; Li, W.; Zhang, K.; Stamnes, J.J. Simultaneous retrieval of aerosols and ocean properties: A classic inverse modeling approach. I. Analytic Jacobians from the linearized CAO-DISORT model. J. Quant. Spectrosc. Radiat. Transf. 2007, 104, 428-449. [CrossRef]

21. Tanaka, A.; Kishino, M.; Doerffer, R.; Schiller, H.; Oishi, T.; Kubota, T. Development of a neural network algorithm for retrieving concentrations of chlorophyll, suspended matter and yellow substance from radiance data of the ocean color and temperature scanner. J. Oceanogr. 2004, 60, 519-530. [CrossRef]

22. Zell, A.; Mache, N.; Hübner, R.; Mamier, G.; Vogt, M.; Schmalzl, M.; Herrmann, K.U. SNNS (Stuttgart Neural Network Simulator). In Neural Network Simulation Environments; Springer: Boston, MA, USA, 1994; pp. 165-186.

23. Jamet, C.; Thiria, S.; Moulin, C.; Crépon, M. Use of a neurovariational inversion for retrieving oceanic and atmospheric constituents from ocean color imagery: A feasibility study. J. Atmos. Ocean. Tech. 2005, 22, 460-475. [CrossRef]

24. Junge, C.E. Atmospheric Chemistry. Adv. Geophy. 1958, 4, 1-108.

25. Brajard, J.; Jamet, C.; Moulin, C.; Thiria, S. Use of a neuro-variational inversion for retrieving oceanic and atmospheric constituents from satellite ocean colour sensor: Application to absorbing aerosols. Neural Netw. 2006, 19, 178-185. [CrossRef]

26. Schiller, H.; Doerffer, R. Neural network for emulation of an inverse model operational derivation of Case II water properties from MERIS data. Int. J. Remote Sens. 1999, 20, 1735-1746. [CrossRef]

27. Stamnes, K.; Li, W.; Fan, Y.; Hamre, B.; Frette, Ø.; Folkestad, A.; Sørensen, K.; Stamnes, J.J. A new algorithm for simultaneous retrieval of aerosol and marine parameters in coastal environments. AIP Conf. Proc. 2013, 1531, 919-922. [CrossRef]

28. Nelder, J.A.; Mead, R. A Simplex Method for Function Minimization. Comput. J. 1965, 7, 308-313. [CrossRef]

29. Lagarias, J.C.; Reeds, J.A.; Wright, M.H.; Wright, P.E. Convergence properties of the Nelder-Mead simplex method in low dimensions. SIAM J. Optim. 1998, 9, 112-147. [CrossRef]

30. Xiong, X.; Barnes, W. An overview of MODIS radiometric calibration and characterization. Adv. Atmos. Sci. 2006, 23, 69-79. [CrossRef]

31. Barnes, W.; Pagano, T.S.; Salomonson, V.V. Prelaunch characteristics of the Moderate Resolution Imaging Spectroradiometer (MODIS) on EOS-AM1. Geosc. Remote Sens. 1998, 36, 1088-1100. [CrossRef]

32. Hamre, B.; Stamnes, S.; Stamnes, K.; Stamnes, J.J. A Versatile Tool for Radiative Transfer Simulations in the Coupled Atmosphere-Ocean System: Introducing AccuRT; Ocean Optics XXII: Portland, ME, USA, 2014.

33. Stamnes, K.; Hamre, B.; Stamnes, S.; Chen, N.; Fan, Y.; Li, W.; Lin, Z.; Stamnes, J. Progress in forward-inverse modeling based on radiative transfer tools for coupled atmosphere-snow/ice-ocean systems: A review and description of the accurt model. Appl. Sci. 2018, 8, 2682. [CrossRef]

34. Holben, B.N.; Eck, T.F.; Slutsker, I.; Tanré, D.; Buis, J.P.; Setzer, A.; Vermote, E.; Reagan, J.A.; Kaufman, Y.J.; et al. AERONET-A federated instrument network and data archive for aerosol characterization. Remote Sens. Environ. 1998, 66, 1-16. [CrossRef]

35. Holben, B.N.; Tanré, D.; Smirnov, A.; Eck, T.F.; Slutsker, I.; Abuhassan, N.; Newcomb, W.W.; Schafer, J.S.; Chatenet, B.; Lavenu, F; et al. An emerging ground-based aerosol climatology: Aerosol optical depth from AERONET. J. Geophys. Res. 2001, 106, 12067-12097. [CrossRef]

36. Ahmad, Z.; Franz, B.A.; McClain, C.R.; Kwiatkowska, E.J.; Werdell, J.; Shettle, E.P.; Holben, B.N. New aerosol models for the retrieval of aerosol optical thickness and normalized water-leaving radiances from the SeaWiFS and MODIS sensors over coastal regions and open oceans. Appl. Opt. 2010, 49, 5545-5560. [CrossRef]

37. Coastcolour. Round Robin Protocal; Version 1.2; Brockmann Consult: Hamburg, Germany, 2010.

38. Babin, M.; Stramski, D.; Ferrari, G.M.; Claustre, H.; Bricaud, A.; Obolensky, G.; Hoepffner, N. Variations in the light absorption coefficients of phytoplankton, nonalgal particles, and dissolved organic matter in coastal waters around Europe. J. Geophys. Res. 2003, 108. [CrossRef]

39. Bricaud, A.; Morel, A.; Babin, M.; Allali, K.; Claustre, H. Variations of light absorption by suspended particles with chlorophyll a concentration in oceanic (case 1) waters: Analysis and implications for bio-optical models. J. Geophys. Res. 1998, 103, 31033-31044. [CrossRef]

40. Babin, M.; Morel, A.; Fournier-Sicre, V.; Fell, F.; Stramski, D. Light scattering properties of marine particles in coastal and open ocean waters as related to the particle mass concentration. Limnol. Oceanogr. 2003, 48, 843-859. [CrossRef]

41. Loisel, H.; Morel, A. Light scattering and chlorophyll concentration in case 1 waters: A reexamination. Limnol. Oceanogr. 1998, 43, 847-858. [CrossRef]

42. Morel, A.; Antoine, D.; Gentili, B. Bidirectional reflectance of oceanic waters: Accounting for Raman emission and varying particle scattering phase function. Appl. Opt. 2002, 41, 6289-6306. [CrossRef] 
43. Broomhead, D.S.; Lowe, D. Radial Basis Functions, Multi-Variable Functional Interpolation and Adaptive Networks; Technical Report; DTIC Document; DTIC: Fort Belvoir, VA, USA, 1988.

44. Fan, L.; Li, W.; Dahlback, A.; Stamnes, J.J.; Stamnes, S.; Stamnes, K. New neural-network-based method to infer total ozone column amounts and cloud effects from multi-channel, moderate bandwidth filter instruments. Opt. Express 2014, 22, 19595-19609. [CrossRef]

45. Bors, A.G. Introduction of the radial basis function (rbf) networks. In Online Symposium for Electronics Engineers; DSP Algorithms: San Jose, CA, USA, 2001; Number 1, pp. 1-7.

46. Nima, C.; Frette, Ø.; Hamre, B.; Stamnes, J.J.; Chen, Y.C.; Sørensen, K.; Norli, M.; Lu, D.; Xing, Q.; Muyimbwa, D.; et al. CDOM absorption properties of natural water bodies along extreme environmental gradients. Water 2019, 11, 1988. [CrossRef]

47. Wright, S.W.; Jeffrey, S.W.; Mantoura, R.F.C. Phytoplankton Pigments in Oceanography: Guidelines to Modern Methods; UNESCO Pub.: Paris, France, 2005.

48. Hagan, M.T.; Demuth, H.B.; Beale, M.H. Neural Network Design; PWS Publishing: Boston, MA, USA, 1996 ; Volume 1.

49. Principe, J.C.; Euliano, N.R.; Lefebvre, W.C. Neural and Adaptive Systems: Fundamentals through Simulations; John Wiley Sons: New York, NY, USA, 2000; Volume 119, p. 514.

50. Fan, Y.; Li, W.; Gatebe, C.K.; Jamet, C.; Zibordi, G.; Schroeder, T.; Stamnes, K. Atmospheric correction over coastal waters using multilayer neural networks. Remote Sens. Environ. 2017, 199, 218-240. [CrossRef]

51. Fan, Y.; Li, W.; Chen, N.; Ahn, J.H.; Park, Y.J.; Kratzer, S.; Schroeder, T.; Ishizaka, J.; Chang, R.; Stamnes, K. OC-SMART: A machine learning based data analysis platform for satellite ocean color sensors. Remote Sens. Environ. 2021, 253, 112236. [CrossRef]

52. Chen, N.; Li, W.; Gatebe, C.; Tanikawa, T.; Hori, M.; Shimada, R.; Aoki, T.; Stamnes, K. New neural network cloud mask algorithm based on radiative transfer simulations. Remote Sens. Environ. 2018, 219, 62-71. [CrossRef] 